\title{
Infants of mothers with systemic connective tissue disease - serological and clinical status in the first year of life; a pilot study
}

\author{
Diana Sochaczewska', Maria Beata Czeszyńska', Katarzyna Fischer², \\ Danuta Bobrowska-Snarska ${ }^{3}$ \\ 'Department of Neonatology, Pomeranian Medical University, Szczecin, Poland \\ ${ }^{2}$ Independent Laboratory for Rheumatologic Diagnostics, Pomeranian Medical University in Szczecin, Poland \\ ${ }^{3}$ Department of Rheumatology Pomeranian Medical University, Szczecin, Poland
}

\section{ABSTRACT}

Background: Neonatal lupus erythematosus (NLE) is an uncommon autoimmune disease caused by transplacental passage of maternal antibodies.

The aim of the study was to investigate whether antinuclear antibodies (ANA) detected in newborns of mothers with systemic connective tissue disease (SCTD) are present after 6 months of age, and whether they are accompanied by clinical symptoms, the so-called NLE.

Material and methods: A prospective pilot study was conducted in a group of 20 full-term newborns (11 males and 9 females) consequently born to mothers with SCTD and 6 newborns ( 3 males and 3 females) of mothers without autoimmune disease. The infants were examined for symptoms of NLE. The ANA profile was evaluated in newborns and repeated at the age of 7 months by using the indirect immunofluorescence technique.

Results: ANA was detected in 16/20 newborns from the study group in titre $1: 40$ to $1: 2560$ and in 4/6 newborns from the control group in titre $1: 40$ to $1: 320$, as well as in 9 of 197 -months-old babies of SCTD mothers. There were no skin lesions, and elevated liver enzymes were found in 8 newborns and haematological changes in 7 newborns. No pathological changes were found in the ECG examination in the neonatal period in any of the children.

Conclusions: Maternal ANAs are detected in newborns and in 7-month-old babies. Despite 80\% of ANA detection in the neonatal period of infants of SCTD mothers and 47\% detection in 7-month-old babies, there were no evident symptoms of NLE besides some elevated levels of liver enzymes and haematological changes.

KEY WORDS:

infants, maternal autoimmune disease, ANAs.

\section{INTRODUCTION}

The human immune system produces antibodies that destroy foreign pathogens. It happens, however, in various disease states, that the immune system produces the socalled autoantibodies that destroy its own tissues and or- gans. Antinuclear antibodies (ANAs) are found in many disorders, as well as in some healthy individuals [1-3]. These disorders include the following: systemic lupus erythematosus, Sjögren syndrome [4], scleroderma [5], mixed connective tissue disease [6], polymyositis, dermatomyositis, autoimmune hepatitis [7], and drug-induced lupus [8].

\section{ADDRESS FOR CORRESPONDENCE:}

Maria Beata Czeszyńska, Department of Neonatology, Pomeranian Medical University, Siedlecka 2, Police,

Poland, e-mail: beataces@pum.edu.pl 
The common tests used for detecting and quantifying ANAs are indirect immunofluorescence and enzyme-linked immunosorbent assay (ELISA). In immunofluorescence, the level of autoantibodies is reported as a titre $[3,9,10]$. This is the highest dilution of the serum at which autoantibodies are still detectable. Positive autoantibody titres at a dilution equal to or greater than $1: 160$ are usually considered as clinically significant. Although positive titres of $1: 160$ or higher are strongly associated with autoimmune disorders, they are also found in $5 \%$ of healthy individuals $[2,3,8]$.

Transplacental transfer is possible in women with ANA antibodies during pregnancy [10-13]. These autoantibodies may cause damage to the developing tissues and increase the risk of bearing infants with neonatal lupus erythematosus (NLE). Approximately $98 \%$ of affected infants have maternal transfer of autoantibodies against Ro/SSA, La/SSB, and, less commonly, U1-RNP [10]. However, only $1-2 \%$ of mothers with these autoantibodies have neonates with NLE, regardless of whether the mothers are symptomatic or not [14]. NLE is a rare acquired autoimmune disease that occurs in 1 of every 20000 live births in the USA [15]. Elsewhere, epidemiology is usually described in small case series [16-18].

NLE refers to a clinical spectrum of cutaneous, cardiac, and systemic abnormalities observed in newborn infants whose mothers have autoantibodies against Ro/ SSA and La/SSB [10, 19-24]. The condition is rare and usually benign and self-limited, but sometimes it may be associated with serious sequelae, like congenital complete atrioventricular block [24]. Data from literature on the incidence of the different clinical manifestations of NLS are difficult to compare because they come mostly from retrospective studies or prospective studies, but as yet no systematic follow-up has been carried out [21-23, 25].

The serum of newborns born to mothers with systemic connective tissue disease shows ANA antibodies passively transferred from the mother. Usually, the presence of maternal antinuclear antibodies is not detected after 6 months of age $[18,26,27]$. There are few studies assessing the behaviour of maternal ANA antibodies in the first year of a child's life [28]. So far, no such studies performed in Poland have been published.

The aim of the study was to investigate whether antinuclear antibodies (ANA) detected in newborns of moth-

TABLE 1. Diagnosed systemic diseases of connective tissue in mothers

\begin{tabular}{|l|c|}
\hline The type of disease & Number of patients \\
\hline Visceral lupus (SLE) & 7 \\
\hline Mixed connective tissue disease & 3 \\
\hline Antiphospholipid syndrome & 9 \\
\hline Rheumatoid arthritis & 1 \\
\hline No autoimmune disease & 6 \\
\hline
\end{tabular}

ers with systemic connective tissue disease are present after 6 months of age, and whether they are accompanied by clinical symptoms, so-called neonatal lupus.

\section{MATERIAL AND METHODS}

A prospective pilot study was conducted in a group of 20 full-term newborns (11 males and 9 females) consequently born to mothers with systemic connective tissue disease and 6 newborns ( 3 males and 3 females) of mothers without autoimmune disease. The type of diagnosed maternal disease is presented in Table 1.

These children were born in the period from June 2015 to June 2017 and were hospitalized in the Department of Neonatology. In the group of children of mothers with systemic connective tissue disease 12 were born by caesarean section and 8 via normal spontaneous delivery. In the group of children of mothers without systemic connective tissue disease 3 were born by caesarean section and 3 via normal spontaneous delivery.

\section{CLINICAL EXAMINATION}

The following parameters were assessed in newborns: gender, gestational age (GA), method of delivery, birth weight, Apgar score, presence of placental transfer of ANA antibodies, liver indicators (bilirubin, aspartate transaminase $[\mathrm{AST}]$, alanine transaminase [ALT], alkaline phosphatase [ALP], gamma-glutamyl transpeptidase [GGT]), and peripheral blood counts. The clinical examination noted the presence of skin lesions in the newborn. Electrocardiography (ECG) was performed in all newborns. The ECG examination was repeated at 7 months of age. At 7 and 12 months of age, the psychomotor and physical development of all 26 infants was evaluated. The development of infants in the first year of life was assessed based on achieving baby development milestones (cognitive, emotional, motor, and social capacities) typical of 7 and 12 months of life.

\section{SEROLOGICAL EXAMINATION}

The ANA profile was evaluated in newborns and repeated at the age of 7 months. Blood for serological tests was collected on the day of the newborn's discharge, and then at the check-up at 7 months of age, as follows: after collection of a clot, the serum was centrifuged, then frozen and stored until the tests were performed. These tests were carried out in the Independent Laboratory for Rheumatological Diagnostics of the Pomeranian Medical University.

IgG antinuclear antibodies (ANA) were assessed on the HEp-2 cell line contaminated by CVCL_0030 cervical adenocarcinoma human HeLa using the indirect immunofluorescence technique and qualitative multiplex assay for monospecific antibodies detection, such as nRNP/ 
TABLE 2. Characteristics of birth status of newborns of mothers with and without systemic connective tissue disease

\begin{tabular}{|c|c|c|}
\hline Features & Mean*/Median** & Ranges \\
\hline Gestational age (week)\#1 & $38.3 \pm 1.0^{*}$ vs. $39 \pm 0.5$ & $37-40$ vs. $38-40$ \\
\hline Birth weight $(\mathrm{g}) \#^{2}$ & $3332.7 \pm 374^{*}$ vs. $3365.0 \pm 396$ & $2660-4400$ vs. $2960-4400$ \\
\hline $1^{\prime}$ Apgar\# $^{3}$ & $9^{* *}$ vs. 10 & $5-10$ vs. $9-10$ \\
\hline $3^{\prime}$ Apgar\#$^{4}$ & $9^{* *}$ vs. 10 & $8-10$ vs. $9-10$ \\
\hline $5^{\prime}$ Apgar\# ${ }^{5}$ & $9^{* *}$ vs. 10 & $8-10$ vs. $9-10$ \\
\hline
\end{tabular}

\# differences between groups not significant (Mann-Whitney test); $p>0.261 ; p>0.332 ; p>0.233 ; p>0.524 ; p>0.715$

TABLE 3. Liver enzymes and blood count parameters in a group of newborns of mothers with connective tissue diseases

\begin{tabular}{|l|c|c|c|c|c|c|c|c|}
\hline Patients & AST (U/I) & ALT (U/I) & GGT (U/I) & ALP (U/I) & WBCs (G/l) & RBCs (T/l) & Hb (g/dl) & PLTs (G/I) \\
\hline 1 & 29 & 12 & 143 & 298 & 9.25 & 4.78 & 15.8 & 278 \\
\hline 2 & 64 & 16 & 55 & 150 & 18.81 & 5.38 & 19.1 & 239 \\
\hline 3 & 24 & 11 & 119 & 121 & 23.88 & 6.04 & 19.9 & 249 \\
\hline 4 & 50 & 10 & 231 & 144 & 21.99 & 4.91 & 17.3 & 222 \\
\hline 5 & 38 & 17 & 44 & 175 & 9.14 & 4.01 & 14.4 & 256 \\
\hline 6 & 49 & 12 & 97 & 127 & 34.75 & 6.78 & 22.9 & 59.9 \\
\hline 7 & 37 & 13 & 63 & 97 & 16.42 & 4.37 & 15.4 & 288 \\
\hline 8 & 32 & 8 & 80 & 113 & 9.52 & 4.48 & 15.5 & 250 \\
\hline 9 & & & & & 11.36 & 5.05 & 18 & 264 \\
\hline 10 & & & & & 21.05 & 5.34 & 18.3 & 304 \\
\hline 11 & 62 & 25 & 113 & 137 & 6.44 & 4.05 & 14.5 & 289 \\
\hline 12 & 52 & 17 & 104 & 121 & 11.3 & 5.81 & 20.3 & 264 \\
\hline 13 & 25 & 13 & 53 & 137 & 22.35 & 4.77 & 17.3 & 242 \\
\hline 14 & 22 & 13 & 601 & & 12.01 & 5.74 & 18.5 & 316 \\
\hline 15 & 113 & 20 & 160 & 147 & 11.01 & 5.42 & 19.1 & 333 \\
\hline 16 & 28 & 7 & 91 & 143 & 9.52 & 3.81 & 13.8 & 268 \\
\hline 17 & 40 & 12 & 58 & 132 & 7.53 & 4.3 & 15.6 & 272 \\
\hline 18 & 30 & 15 & 25 & 138 & 7.73 & 4.48 & 16.4 & 221 \\
\hline 19 & 33 & 143 & 135 & 7.86 & 5.83 & 20.6 & 297 \\
\hline 20 & & & & & 6.01 & 4.92 & 17.7 & 257 \\
\hline
\end{tabular}

ALT - alanine transaminase; AST - aspartate transaminase; ALP - alkaline phosphatise; GGT - gamma-glutamyl transpeptidase; RBCs - red blood cells; WBCs - white blood cells; Hb - haemoglobin; PLTs - platelets

Sm, Sm, SS-A (native), Ro-52, SS-B, Scl-70, PM/Scl, Jo-1, CENP B, PCNA, dsDNA, nucleosomes, histones, ribosomal P protein, AMA M2, and DFS-70 performed with line-blot method (EUROIMMUN AG Medizinische Labordiagnostika tests, Luebeck, Germany).

Mothers were informed about the purpose of the study and consented to its implementation in their infants in the neonatal period and at 7 months of age. The research was carried out as part of the research topics of the Department of Neonatology of the Pomeranian Medical University (138-S1/2014).

Statistical analyses were carried out with the help of the STATA 11 statistical program, license number 30110532736. Continuous variables were checked for normality of distribution with a Kolmogorov-Smirnov test. Median, minimum, and maximum values were used to describe the variables (in cases when the normal distribution assumptions were not met), while in other cases the mean and standard deviation were calculated. Statistical differences between continuous variables of the different groups were checked with a Mann-Whitney $\mathrm{U}$ test.

\section{RESULTS}

The characteristics of the birth status of the newborns of mothers with and without systemic connective tissue disease are presented in Table 2. There were no significant differences in mean GA and mean birthweight while 1-, 3-, and 5-minute Apgar scores were lower (median 9 points vs. 10 points) between newborns of mothers with and without systemic connective tissue disease (Table 2). 
TABLE 4. Liver enzymes and blood count parameters in a group of newborns of mothers without autoimmune disease

\begin{tabular}{|l|c|c|c|c|c|c|c|c|}
\hline Patients & AST (U/I) & ALT (U/I) & GGT (U/I) & ALP (U/I) & Leu (G/l) & Er (T/I) & Hb (g/dl) & PLT (G/I) \\
\hline 1 & 35 & 7 & 74 & 121 & 9.16 & 5.41 & 18.9 & 173 \\
\hline 2 & 39 & 27 & 86 & 159 & 11.5 & 4.94 & 17.3 & 187 \\
\hline 3 & 68 & 23 & 74 & 74 & 16.2 & 5.81 & 19.4 & 336 \\
\hline 4 & 42 & 11 & 97 & 240 & 27.37 & 5.56 & 21.2 & 348 \\
\hline 5 & 57 & 22 & 88 & 111 & 10.64 & 4.97 & 15.5 & 328 \\
\hline 6 & 32 & 11 & 80 & 161 & 20.16 & 5.51 & 18.9 & 275 \\
\hline
\end{tabular}

Explanation of abbreviations: alanine transaminase (ALT), aspartate transaminase (AST), alkaline phosphatase (ALP), and gamma-glutamyl transpeptidase (GGT); red blood cells (RBCS), white blood cells $(W B C S)$, haemoglobin $(H b)$, platelets (PLTs).

TABLE 5. ANA profile in newborns and at 7 months of age

\begin{tabular}{|c|c|c|c|c|}
\hline Patients & Maternal ANA titre & Maternal diagnosis & Neonatal ANA titre & ANA titre at 7 months of age \\
\hline 1.W Male & & No autoimmune disease & 320 & \\
\hline 2. S Female & & No autoimmune disease & Not detected & \\
\hline 3. K Female & 80 & No autoimmune disease & 40 & \\
\hline 4. Ch Male & & No autoimmune disease & 40 & \\
\hline 5. R Male & & No autoimmune disease & 40 & Not detected \\
\hline 6. M Female & & No autoimmune disease & Not detected & Not detected \\
\hline 7.S Male & 320 & Lupus erythematosus & 40 & Not detected \\
\hline 8. M Male & & Antiphospholipid syndrome & Not detected & Not detected \\
\hline 9. A Female & & Lupus erythematosus & 160 & Not detected \\
\hline 10. G Male & & Lupus erythematosus & 640 & 80 \\
\hline 11. M Female & & Antiphospholipid syndrome & 40 & 40 \\
\hline 12. Sz Male & & Mixed connective tissue disease & 80 & 40 \\
\hline 13. S Female & 160 & Antiphospholipid syndrome & 40 & Not detected \\
\hline 14. K Female & 160 & Lupus erythematosus & 160 & Not detected \\
\hline 15. B Female & & Rheumatoid arthritis & 320 & 40 \\
\hline 16. Cz Female & 2560 & Lupus erythematosus & 640 & 40 \\
\hline 17. WP Male & & Antiphospholipid syndrome & Not detected & Not detected \\
\hline 18. Cz Male & 1280 & Lupus erythematosus & 320 & Not detected \\
\hline 19. K Female & & Antiphospholipid syndrome & Not detected & Not detected \\
\hline 20.Z Male & & Antiphospholipid syndrome & 40 & Not detected \\
\hline 21. N Female & & Antiphospholipid syndrome & 40 & 40 \\
\hline 22. L Male & & Antiphospholipid syndrome & 40 & \\
\hline 23. C Male & 10240 & Mixed connective tissue disease & 2560 & 40 \\
\hline 24. 0 Male & 640 & Lupus erythematosus & 160 & 40 \\
\hline 25. B Male & & Antiphospholipid syndrome & Not detected & Not detected \\
\hline 26. KK Female & & Mixed connective tissue disease & 160 & 40 \\
\hline
\end{tabular}

The liver enzyme and blood count parameters in the group of newborns of mothers with connective tissue diseases are presented in Table 3 . In the group of 20 newborns of mothers with systemic connective tissue disease, AST values averaged $45.69 \mathrm{U} / \mathrm{I}$ and ranged from 22 to $113 \mathrm{U} / \mathrm{I}$. Increased values were noted in 1 newborn. ALT values averaged $15.43 \mathrm{U} / \mathrm{I}$ and they ranged from 22 to $113 \mathrm{U} / \mathrm{I}$. GGT values averaged $116.47 \mathrm{U} / \mathrm{I}$ and the range was from 74 to $601 \mathrm{U} / \mathrm{I}$. Increased values were noted in 5 (20\%) newborns. The ALP values averaged $148 \mathrm{U} / \mathrm{I}$ and the range was from 25 to $298 \mathrm{U} / \mathrm{I}$. Increased values were noted in 2 newborns. In the control group increased ALP values were found in 1 newborn (Table 4).

In a group of 20 newborns of mothers with systemic connective tissue disease, the mean leukocyte count was $14.34 \mathrm{G} / \mathrm{l}$ and it ranged from 6.01 to $34.75 \mathrm{G} / \mathrm{l}$. The mean 
red blood cell (RBC) count was $5.1 \mathrm{~T} / 1$ and it ranged from 3.81 to $6.78 \mathrm{~T} / \mathrm{l}$. The haemoglobin level averaged $17.79 \mathrm{~g} / \mathrm{dl}$ and the range was from 13.8 to $22.9 \mathrm{~g} / \mathrm{dl}$. The platelet count averaged $262.15 \mathrm{G} / \mathrm{L}$ and the range was from 59.9 to $348 \mathrm{G} / 1$ (Table 3). In the control group the leukocyte count, RBC, haemoglobin level, and platelet count were within normal ranges (Table 4).

The course of jaundice in 18 newborns of mothers with systemic connective tissue disease was physiological, in 2 of the mothers with SLE the total bilirubin levels were above $15 \mathrm{mg} / \mathrm{dl}$ and these newborns required phototherapy. No adverse changes on the skin of newborns were observed during phototherapy. The course of jaundice in 6 newborns of mothers without autoimmune disease was physiological.

No pathological changes were found in the ECG examination in the neonatal period in any of the children in the group of mothers with systemic connective tissue disease and in mothers without such disease. The ECG examination was repeated at 7 months of age in 19 children from the assessed group from mothers with autoimmune disease, including 5 children with abnormalities in the ECG recording. There was no atrioventricular block in any of the children.

At 7 months of age, the psychomotor and physical development of all 26 assessed children was normal. At 12 months of age, the psychomotor development of all children of mothers with connective tissue disease was normal. No child required permanent medication. Physical development was assessed on the basis of the body weight related to WHO percentile grids from 2012. In a group of 19 children, 9 had normal body weight, 1 child decreased by one deviation, another child decreased by 2 deviations, another 4 children increased by 2 deviations, and another 4 children increased by 1 deviation.

ANA titres in mothers, newborns, and after 7 months of age are presented in Table 5.

ANA titre during the third trimester of pregnancy was determined in $7 / 20$ mothers diagnosed with autoimmune disease. It ranged from $1: 160$ to $1: 10240$. One of the mothers without diagnosed connective tissue disease was found to have ANA in titre $1: 80$. Out of the group of 20 newborns of mothers diagnosed with autoimmune disease, 4 (20\%) had no presence of ANA. For $16(80 \%)$ it was from $1: 40$ to $1: 2560$. In $2 / 6$ of infants of mothers without connective tissue disease ANA was not detected, and in 4/6 ANA was present at $1: 40$.

At 7 months of age, the ANA titre was determined in $2 / 6$ of infants from the group without maternal autoimmune disease, and no antibodies were detected. In the group of infants of mothers with systemic connective tissue disease, 19 out of 20 assessed in the neonatal period were examined at 7 months of age. In 10 of them, the presence of ANA was not detected, and in 9 the titre ranged from $1: 40$ to $1: 80$.

\section{DISCUSSION}

The best method of determining ANA is the immunofluorescence method [3]. The method was also used in this study, and the presence of ANA was detected in 16/20 (80\%) of the examined newborns of mothers with connective tissue disease. A similar frequency was reported in the studies by Motta et al. [29]. They found ANA in $18 / 22(81.2 \%)$ of the examined newborns of mothers with autoimmune diseases. In a study of Yang et al. a total of 8 cases matched the criteria for diagnosis of NLE from September 2003 to February 2006; ANA was positive in 7 newborns and in all mothers [11]. Sanchez-Manubens et al. performed antibody assays in 14 of the 39 infants born to mothers with autoimmune disease (35.8\%). Among 14 children, in 4 (28.6\%) of them placental transfer of maternal antibodies was detected [30].

In the course of this study, the ANA titres in pregnancy were obtained from 8 mothers. The ANA level detected in newborns was most often lower than in their mothers during pregnancy, but the higher it was in the mothers, the proportionally higher it was in the examined newborns. Beck et al., on the other hand, state that the homogenous antinuclear antibody was found in the sera of 3 pregnant women with systemic lupus erythematosus in titres similar to those in the newborns' sera [31].

It has been shown that the level of maternal antibodies, rather than their presence, is associated with foetal tissue injury [20]. However, only some neonates (about 2\%) exposed to these antibodies develop complications [14]. Therefore, other factors such as titres of maternal antibodies, genetic predisposition, and environmental factors such as viral infection may be involved.

The morbidity and mortality of SLE in childhood depend on the organ systems affected $[3,15,23]$. The most common are skin lesions [19, 23, 25, 26, 32, 34, 35]. In the present study no skin changes in the neonatal period were found. The factor causing these changes may be the phototherapy used in the treatment of hyperbilirubinaemia in the newborn [14]. In the analysed group of newborns, 2 children underwent phototherapy due to excessive neonatal jaundice. However, no adverse effects of phototherapy on the skin of treated newborns were found.

Children with NLE have an excellent long-term outcome when only skin lesions are present [33]. The cutaneous lesions usually disappear by 6 months of age, coincident with the clearance of maternal antibodies from the child's circulation $[15,26,27,34]$.

The most common extra-cutaneous manifestation is cardiac involvement, which occurs in $2 \%$ of newborns whose mothers are positive for Ro/SSA or La/SSB [9, 10, 24]. The most serious complication is atrioventricular block, which can be diagnosed in utero with a routine ultrasound scan and is commonly referred to as congenital complete block $[15,24]$. In the study of Singalavanija et al. 
complete heart block was found in $14.7 \%$ of cases $(n=5 / 34)$. Anti-Ro/SSA and anti-La/SSB were positive in $91.1 \%$ and $58.8 \%$ of cases, respectively [35].

In this study there were no cases of atrioventricular block diagnosed during pregnancy. Neonatal ECG was performed before discharging babies from the neonatal department, and in all analysed cases the ECG was normal. Similarly to our study, other researches performed an ECG and echocardiography, which were normal during the neonatal period $[30,34]$. We repeated an ECG at 7 months of life, and there were non-specific changes in $5 / 19(26.3 \%)$ children.

In our study 3 (15\%) newborns of mothers with autoimmune disease had haematological problems, among them 1 had thrombocytopaenia, 1 suffered from leukocytopaenia, and another 1 had anaemia. Li described that 44 cases out of 94 analysed had haematological problems including 28 with thrombocytopaenia, 11 with leukocytopaenia, and 34 with anaemia [16]. Singalavanija et al. noticed that $50 \%$ cases had haematological problems including anaemia (29.4\%), and anaemia with thrombocytopaenia (20.6\%) [36]. Zuppa noticed that haematological NLS features (such as anaemia, neutropaenia, thrombocytopaenia) were found at birth and during follow-up in several patients, in all cases without clinical manifestations and in most cases with complete normalization at 9 months. [22]

Although biochemical evidence of liver disease is common in patients with systemic lupus erythematosus (SLE), clinical liver disease is uncommon [14]. The clinical pictures of hepatobiliary involvement may take the forms of elevation of liver enzymes (such as aspartate aminotransferase and alanine aminotransferase) and/or conjugated hyperbilirubinaemia occurring a few weeks or months after birth and resolving thereafter [11, 14, 22].

In the present study, in $20 \%$ newborns of mothers with autoimmune disease, elevation of GGT, in $4 \%$ of aspartate aminotransferase, and in $8 \%$ of ALP were noticed. In the study of Li 30 cases had hepatic abnormality, including 24 liver disfunction, 22 hepatomegaly, 6 splenomegaly, and 3 cholestasis [16]. Mild and transient elevation of aminotransferases between 3 and 6 months of life were found in $56 \%$ and $40 \%$ of patients, respectively, in the study of Zupppa [22].

What is important and should be emphasised is that the persistence of maternal ANA antibodies in the infant's blood is longer than previously thought. In the present study, 9/19 tested children of mothers with autoimmune disease were found to have ANA antibodies at 7 months of age, ranging from $1: 40$ to $1: 80$. In 2 cases, the titre remained at the same level and amounted to $1: 40$, in the remaining cases the titre was decreasing compared to the values found in the neonatal period. Longer persistence of maternal antibodies in the children is associated with the possibility of longer adverse effects on the developing child. In the literature, the time of pres- ence of maternal anti-nuclear antibodies is defined as the period up to 6 months of age $[15,26,27,34]$.

Children who have had NLE are probably at increased risk for autoimmunity later in life, sometimes as early as pre-adolescence, but the magnitude of the risk for the children is not known [37]. Only a small percentage of babies exposed to maternal autoantibodies to Ro and/ or La develop NLE. The factors governing which babies develop disease and, if disease develops, which organs will be affected have yet to be fully elucidated [12]. It seems justified to say that these children, whose antibody titre is constantly detectable in the following months of life, require long-term observation with periodic ECG control.

There are some limitations of our study: a small number of infants involved, and just paediatric examination without haematological and biochemical (liver enzymes) laboratory test at the age of 3 and 7 months.

\section{CONCLUSIONS}

Maternal ANAs are detected in newborns and in 7-month-old babies.

Despite $80 \%$ detection of ANAs in the neonatal period of infants of mothers with autoimmune disease and $47 \%$ detection in 7-month-old babies, there were no evident signs of neonatal lupus besides some elevated levels of liver enzymes and haematological changes.

\section{DISCLOSURE}

The authors declare no conflict of interest.

\section{REFERENCES}

1. Arroyava CM, Giambrone MJ, Rich KC, Walaszek M. The frequency of antinuclear antibody (ANA) in children by use of mouse kidney (MK) and human epithelial cells (HEp-2) as substrates. J Allergy Clin Immunol 1988; 82: 741-744.

2. Tan EM, Feltkamp TEW, Smolen JS, et al. Range of antinuclear antibodies in "healthy" individuals. Arthritis Rheum 1997; 40: 16011611.

3. Li X, Liu X, Cui J, et al. Epidemiological survey of antinuclear antibodies in healthy population and analysis of clinical characteristics of positive population. J Clin Lab Anal 2019; 33: e22965.

4. Cervera R, Font J, Ramos-Casals M, et al. Primary Sjögren's syndrome in men: clinical and immunological characteristics. Lupus 2000; 9: 61-64.

5. Barnett AJ, McNeilage LJ. Antinuclear antibodies in patients with scleroderma (systemic sclerosis) and in their blood relatives and spouses. Ann Rheum Dis 1993; 52: 365-368.

6. Burdt MA, Hoffman RW, Deutscher S, et al. Long-term outcome in mixed connective tissue disease: Longitudinal clinical and serologic findings. Arthritis Rheum 1999; 42: 899-909.

7. Obermayer-Straub P, Strassburg CP, Manns MP. Autoimmune hepatitis. J Hepatol 2000; 32 (1 Suppl): 181-197.

8. Kavanaugh A, Tomar R, Reveille J, et al.Guidelines for clinical use of the antinuclear antibody test and tests for specific autoantibodies to nuclear antigens. American College of Pathologists. Arch Pathol Lab Med 2000; 124: 71-81. 
9. Kumar Y, Bhatia A, Minz RW. Antinuclear antibodies and their detection methods in diagnosis of connective tissue diseases: a journey revisited. Diagn Pathol 2009; 4: 1-10.

10. Hon KL, Alexander KC, Leung AKC. Neonatal lupus erythematosus. Autoimmune Dis 2012; 2012: 301274.

11. Yang Q, Shao X-M, Cao Y, et al. Neonatal lupus erythematosus: analysis of 8 cases. Zhonghua Er Ke Za Zhi 2008; 46: 18-21.

12. Lee LA. Transient autoimmunity related to maternal autoantibodies: neonatal lupus. Autoimmun Rev 2005; 4: 207-213.

13. Herrera-Esparza R, Bollain-y-Goytia JJ, Avalos-Díaz E. Pathogenic effects of maternal antinuclear antibodies during pregnancy in women with lupus. Rheum Rep 2014; 6: 5545.

14. Shahian M, Khosravi A, Anbardar MH. Early cholestasis in neonatal lupus erythematosus. Ann Saudi Med 2011; 31: 80-82.

15. Buyon JP. Neonatal Lupus: bedside to bench and back. Scand Rheumatol 1996; 25: 271-276.

16. Li L, Dong GF, Han FZ, et al. Neonatal lupus erythematosus: a report of 7 cases and review of 87 cases of China. Zhonghua Er Ke Za Zhi 2011; 49: 146-150.

17. Liu J, Yang YH, Lin YT, Chiang BL. Clinical characteristics of neonatal lupus erythematosus. J Microbiol Immunol Infect 2001; 34: 265-268.

18. Liu W, Ma DL. Neonatal lupus erythematosus. CMAJ 2020; 192: E163.

19. Wisuthsarewong W, Soongswang J, Chantorn R. Neonatal lupus erythematosus: clinical character, investigation, and outcome. Pediat Dermat 2011; 28: 115-121.

20. Jaeggi E, Laskin C, Hamilton R, et al. The importance of the level of maternal anti-Ro/SSA antibodies as a prognostic marker of the development of cardiac neonatal lupus erythematosus. A Prospective Study of 186 antibody-exposed fetuses and infants. J Am Coll Cardiol 2010; 55: 2778-2784

21. Inzinger M, Salmhofer W, Binder B. Neonatal Lupus Erythematosus and its clinical variability. J Dtsch Dermatol Ges 2012; 10: 407-411.

22. Zuppa AA, Fracchiolla A, Cota F, et al. Infants born to mothers with anti-SSA/Ro autoantibodies: neonatal outcome and follow-up. Clin Pediatr 2008; 47: 231-236.

23. Diaz-Frias J, Badri T. Neonatal Lupus Erythematosus. In: StatPearls Treasure. StatPearls Publishing LLC, Island 2020.

24. Kociszewska-Najman B, Jaskólska M, Joanna Schreiber-Zamora J, et al. Toczeń rumieniowaty noworodków. Stanowisko Zespołu Ekspertów w sprawie diagnostyki, monitorowania oraz leczenia matki i noworodka. Gin Perinat Prakt 2020; 1: 33-43.

25. Torres-Navarro I, López-Montesinos B, Évole-Buselli M. Neonatal lupus. An Pediatr (Barc) 2021; 94: 122-123.

26. Izmirly PM, Llanos C, Lee LA, et al. Cutaneous manifestations of neonatal lupus and risk of subsequent congenital heart block. Arthritis Rheum 2010; 62: 1153-1157.

27. Brucato A, Frassi M, Franceschini F, et al. Risk of congenital complete heart block in newborns of mothers with anti-Ro/SSA antibodies detected by counterimmunoelectrophoresis: a prospective study of 100 women. Arthritis Rheum 2001; 44: 1832-1835.

28. Zuppa AA, Riccardi R, Frezza S. Neonatal lupus: Follow-up in infants with anti-SSA/Ro antibodies and review of the literature. Autoimmun Rev 2017; 16: 427-432.

29. Motta M, Chirico G, Biasini-Rebaioli Ch, et al. Anticardiolipin and anti-beta2 glycoprotein I antibodies in infants born to mothers with antiphospholipid antibody-positive autoimmune disease: a follow-up study. Am J Perinatol 2006; 23: 247-251.

30. Sanchez-Manubens J, Ortiz-Santamaria V, Coll Sibina MT, et al. Newborns whose mother has autoimmune disease. A community hospitals' experience. Reumatol Clin 2013; 9: 161-165.

31. Beck JS, Oakley CL, Rowell NR. Transplacental passage of antinuclear antibody study in infants of mothers with systemic lupus erythematosus. Arch Dermatol 1966; 93: 656-663.
32. Silverman E, Jaeggi E. Non-cardiac manifestations of neonatal lupus erythematosus. Scan J Immunol 2010; 72: 223-225.

33. Sun W, Yuan TM, Chen LH, Yu HM. Neonatal lupus erythematosus: three case reports and review of the chinese literature. Clin Pediatr 2010; 49: 627-634.

34. Savino F, Viola S, Tarasco V, et al. Neonatal lupus erythematosus: a cutaneous cases based update. Ital J Pediatr 2016; 42: 1.

35. Neiman A, Lee L, Weston W, Buyon J. Cutaneous manifestations of neonatal lupus without heart block: characteristics of mothers and children enrolled in a national registry. J Pediatr 2000; 137 : 674-680.

36. Singalavanija S, Limpongsanurak W, Aoongern S. Neonatal lupus erythematosus: a 20-year retrospective study. J Med Assoc Thai 2014; 97 Suppl 6: S74-S82.

37. Martin V, Lee LA, Askanase AD, et al. Long-term follow-up of children with neonatal lupus and their unaffected siblings. Arthritis Rheum 2002; 46: 2377-2383. 